\title{
MULHER MARAVILHA (2017): UM FILME DE SEGUNDA GUERRA MUNDIAL AMBIENTADO NA PRIMEIRA GUERRA MUNDIAL
}

\author{
José Otaviano da Mata Machado ${ }^{1}$
}

Resumo: Mulher Maravilha, adaptação para o cinema de 2017, dirigida por Patty Jenkins, oferece um olhar contemporâneo sobre a Primeira Guerra Mundial. Contudo, as histórias em quadrinhos que servem de material fonte para a adaptação são produtos da chamada "Era de Ouro" dos quadros de super-herói estadunidenses, e são marcadamente produtos do período da Segunda Guerra Mundial. Portanto, a adaptação efetua um processo de deslocamento cronológico da ambientação tradicional da personagem Mulher Maravilha. Esse deslocamento tem efeitos diretos na recepção da obra - efeitos em grande parte causado pelas profundas distinções entre os mitos de cada uma das duas guerras mundiais (HYNES, 1992, 1998). Esse trabalho investiga os efeitos desse deslocamento e suas consequências para um olhar contemporâneo sobre a Primeira Guerra Mundial.

Palavras-chave: Primeira Guerra Mundial; Segunda Guerra Mundial; Mulher Maravilha.

Abstract: Wonder Woman, a 2017 movie adaptation directed by Patty Jenkins, offers a contemporary look into the First World War. However, the comic books by which the adaptation was inspired are products of the so-called "Golden Age" of American super-hero comic books, and are notably a product of the Second World War. Therefore, the adaptation effects a process of chronological displacement of Wonder Woman's traditional setting. Such displacement has direct effects on how the work is perceived - effects caused, in great part, by the profound differences between the myths of each of the two World Wars (HYNES, 1992, 1998). The present work investigates the effects of this displacement, and its consequences for a contemporary look on the First World War.

Keywords: First World War; Second World War; Wonder Woman.

1 Doutorando em Teoria da Literatura e Literatura Comparada (Bolsista CAPES) na Universidade Federal de Minas Gerais. 


\section{Now I know that only love can truly change the world.}

A primeira metade da década de 1940 é conhecida por historiadores dos quadrinhos estadunidenses como a "Era de Ouro" do gênero (QUATTRO, 2004). Essa categorização faz parte de uma divisão que separa a história dos quadrinhos de super-herói estadunidenses em 4 "eras", marcadas por transformações na indústria, no público consumidor e na sociedade americana. A Era de Ouro é a primeira dessas eras, iniciada em 1938 com a publicação de Action Comics \#1 - a primeira aparição do personagem Super-Homem, o grande arquétipo dos personagens de super-herói, criado por Jerry Siegel e Joe Shuster (SPIEGELMAN, 2019). O boom das histórias em quadrinhos de super-heróis nos Estados Unidos é indissociável da Segunda Guerra Mundial, do advento do Fascismo na Europa e do impacto de ambos na consciência americana da época. Art Spiegelman discute esse aspecto em um recente ensaio sobres os 80 anos da editora Marvel Comics - censurado pela própria editora ${ }^{2}$ :

(...) talvez valha a pena ressaltar (não por orgulho étnico, mas para jogar luz sobre a crueza e os temas específicos dos primeiros gibis) que os pioneiros dessa mídia embrionária que moravam em Nova York eram predominantemente judeus e de outras minorias. Não foram só Siegel e Shuster, mas toda uma nova geração de imigrantes e seus filhos - os mais vulneráveis às mazelas da Grande Depressão - , que acompanhavam de perto a ascensão do virulento antissemitismo na Alemanha. Foram eles que criaram os Übermenschen norte-americanos, que lutavam por uma nação que, ao menos nominalmente, receberia "seus fatigados, seus pobres, suas massas encurraladas que anseiam respirar liberdade...", como dizem os versos gravados na Estátua da Liberdade. (SPIEGELMAN, 2019)

Não por acaso, a Era de Ouro testemunhou uma profusão de personagens patrióticos vestindo as cores da bandeira estadunidense e enfrentando agentes e soldados nazistas tanto em solo americano quanto europeu. Além do hoje famoso Capitão América, criação de Joe Simon e Jack Kirby para a editora Timely Comics (hoje Marvel Comics), mais uma infinitude de super-heróis patrióticos desfilou pelas páginas desses quadrinhos, com nomes como Mr. America (DC Comics), The Flag (Ace Comics), Captain Flag (MLJ Comics) e American Crusader (Nedor Comics). Poucos personagens dessa era sobreviveram à crise que atingiu a indústria de quadrinhos americana após o final da Segunda Guerra. Além dos já mencionados Capitão América e Super-Homem, galgaram também lugares consolidados na cultura pop o Batman, o Aquaman, o Arqueiro Verde e uma das poucas personagens femininas da época: a Mulher Maravilha.

A personagem Mulher Maravilha (Wonder Woman, no original) teve sua primeira aparição na oitava edição do quadrinho All Star Comics, publicada em outubro de 1941.

2 O ensaio foi encomendado pela editora Folio Society como uma introdução a um livro ilustrado comemorativo dos 80 anos da Marvel Comics. Contudo, o ensaio foi vetado pela própria Marvel - coeditora da publicação - devido a menções críticas ao presidente estadunidense Donald Trump. No ensaio, Spiegelman o chama de "Caveira Laranja”, em menção ao clássico vilão "Caveira Vermelha", arqui-inimigo do herói da Era de Ouro Capitão América. 
Criada pelo psicólogo William Moulton Marston - criador do polígrafo, autodeclarado feminista e defensor de práticas fetichistas como forma de transformação social (LEPORE, 2014) -, a personagem rapidamente se transformou em um símbolo de destaque em meio à miríade de personagens que povoavam as páginas das revistinhas da Era de Ouro.

Como é de praxe em histórias em quadrinhos de super-heróis de longa publicação, a história de origem da Mulher Maravilha sofreu diversas alterações com o passar das décadas, mas é possível traçar alguns elementos principais que se mantiveram consistentes. Diana - o alter ego de Mulher Maravilha - é uma guerreira amazona de uma ilha isolada no meio do oceano, onde homens são proibidos de entrar. Um dia, o avião do piloto da Força Aérea dos Estados Unidos Steve Trevor cai na ilha e é encontrado pela guerreira, que se apaixona pelo soldado. Diana conquista, com sua vitória em um torneio de combate, o direito de sair da ilha para escoltar Steve Trevor de volta para o "Mundo dos Homens". Ela ganha um uniforme especial para essa missão, um presente de sua mãe Hipólita, rainha das amazonas. De posse da icônica vestimenta, dos invencíveis Braceletes da Submissão - capazes de defletir balas - e do Laço da Verdade - que consegue extrair confissões de qualquer pessoa -, a Mulher Maravilha inicia suas aventuras nos Estados Unidos dos anos 1940.

Como outros super-heróis do período, as aventuras da heroína eram marcadas pelo clima de patriotismo da Segunda Guerra Mundial, com aventuras que frequentemente envolviam o desmantelamento de células de espionagem nazistas em território americano. Suas estórias são indissociáveis de seu contexto de publicação nos anos 1940.

Dito isso, o longa-metragem Mulher Maravilha (Wonder Woman, 2017), da diretora Patty Jenkins, apresenta um deslocamento notável e digno de análise: no filme, a jornada de Diana para longe de sua ilha-natal Themscyra em direção ao "Mundo dos Homens" não se dá durante a Segunda Guerra Mundial, mas durante a Primeira Guerra Mundial. Esse deslocamento temporal tem implicações diretas no enredo: no filme, Steven Trevor não é um piloto da Força Aérea dos Estados Unidos, mas sim um espião do Serviço de Inteligência Britânico, que cai na ilha de Themscyra fugindo de uma unidade do exército alemão que o identifica espionando um laboratório secreto dos Poderes Centrais no império Turco-Otomano, dias antes da assinatura do armistício que colocaria um fim no conflito. Quando Steve Trevor conhece Diana após ser resgatado por ela, ele a diz que precisa voltar à Inglaterra para relatar a seus superiores uma descoberta terrível: o general Erich Ludendorff - um dos vilões do filme, contraparte ficcional de uma figura histórica central nos esforços de guerra alemães a partir de 1916 - estaria desenvolvendo, junto à cientista Isabel Maru - conhecida como “Doutora Veneno", uma vilã clássica nos quadrinhos da Mulher Maravilha - uma versão mais fatal do gás mostarda, contra a qual o uso de máscaras de gás seria inútil. O plano de Ludendorff seria o de liberar o gás nas trincheiras do front ocidental antes da assinatura do armistício. Ao ouvir o relato de Steve Trevor sobre suas descobertas, Diana se convence de que a Primeira Guerra Mundial é, na verdade, um plano do deus da guerra Ares - um deus sobre o qual sua mãe lhe contava aterradoras estórias desde sua infância. Entendendo que a missão das amazonas é a de proteger o mundo dos homens dos planos de Ares, Diana decide ir para a Inglaterra com Trevor com a promessa de que o soldado a levaria ao front, onde ela acreditava que poderia encontrar Ares e enfrentá-lo em combate. A heroína acredita que ao matar o deus, a guerra instantaneamente acabaria - uma hipótese que de fato se confirma ao final do filme. 
A escolha de deslocar a ambientação de Mulher Maravilha de suas origens na Segunda Guerra Mundial para uma reinvenção da personagem na Primeira Guerra foi discutida e justificada pelo roteirista Allan Heinberg, pelo produtor Zack Snyder e pela diretora Patty Jenkins. Dentre as justificativas, eles mencionam os paralelos entre o mundo durante a década de 1910 e o momento histórico presente: "estamos em um mundo muito 'Primeira Guerra Mundial' com o nacionalismo e com o quão fácil seria começar um conflito global" (SPERLING, 2017). ${ }^{3}$ Heinberg acrescenta ainda o interesse em retratar um mundo que pela primeira vez testemunhava uma guerra automatizada, com o advento da metralhadora e do gás. A diretora Patty Jenkins ainda menciona o interesse por ambientar o filme em uma guerra em que "não era claro quem estava certo".

As características da Primeira Guerra Mundial elencadas pela equipe de produção de Mulher Maravilha de fato são traços distintivos do conflito - são parte do "mito da guerra" (a ser discutido a seguir). Contudo, cabe questionar se de fato o longa-metragem trabalha esses aspectos - ou seja, há mesmo um questionamento do papel do nacionalismo? O horror da guerra automatizada é realmente retratado? Existe de fato uma ambiguidade moral no filme? A hipótese desse artigo é a de que a resposta é negativa para todas essas perguntas. Embora Mulher Maravilha explore, deveras, tais questões, sua abordagem consiste em um tratamento estético e narrativo muito distinto do que se espera de narrativas de Primeira Guerra Mundial - e, arrisco dizer, muito mais apologético à própria guerra. O que busco evidenciar a seguir é como esse discurso em certa medida apologético surge de estratégias narrativas e visuais que ecoam não a forma como a Primeira Guerra Mundial foi historicamente representada, mas sim, a representação da Segunda Guerra Mundial. De tal forma, o argumento central desse trabalho pode ser resumido como: Mulher Maravilha é um filme de Segunda Guerra Mundial ambientado na Primeira Guerra Mundial. Porém, antes de aprofundar esse argumento, cabe definir de forma mais explícita o que quero expressar por "um filme de Segunda" ou "de Primeira Guerreira Mundial” - ou seja, explicitar quais são os "mitos" de ambos os conflitos.

\section{O MITO DA GUERRA}

A expressão "mito" é usada para definir diferentes categorias em diferentes campos das humanidades, e essa polissemia da palavra frequentemente gera desencontros. O conceito a ser trabalhado aqui é "Mito da guerra", uma categoria elaborada por Samuel Hynes em, centralmente, duas obras ( $A$ War Imagined e The Soldiers' Tale) para designar a narrativa coletiva que emerge a partir de um conflito bélico. A categoria deve ser entendida aqui como uma definição própria, que emerge dos estudos de literaturas de guerra, e não como uma categoria derivada de outras definições de "mito" propostas pela antropologia ou pela crítica literária. Hynes define o "mito da guerra" da seguinte forma, em duas ocasiões diferentes:

3 "We are in a very WWI world today with nationalism and how it would take very little to start a global conflict" 
Eu uso esta expressão [o Mito da Guerra] não para implicar uma falsificação da realidade, mas uma versão imaginativa dela, a estória da guerra que evolui, e que veio a ser aceita enquanto verdade. A construção dessa estória iniciou durante a guerra, e cresceu nos anos seguintes, assimilando em seu caminho aquilo que era compatível com seus julgamentos, e rejeitando o que não era. O Mito não é a Guerra por inteiro: é um conto que confirma um conjunto de atitudes, uma ideia do que foi a guerra e do que ela significou. (HYNES, 1992, loc. 74). ${ }^{4}$

[Por mito] eu quero dizer a narrativa simplificada que evolui a partir de uma guerra, através da qual ela é significada: uma Guerra Boa, uma Guerra Má, uma Guerra Necessária. Mitos parecem ser socialmente necessários, como julgamentos ou justificativas para os terríveis custos da guerra, mas eles assumem forma às custas da particularidade e da ordinariedade da experiência (...). O mito de uma guerra conta o que é imaginável e administrável. (HYNES, 1998, p.xiii) ${ }^{5}$

Assim, o Mito da Guerra pode nos oferecer um pano de fundo sobre o qual é possível trabalhar, comparativamente, uma "narrativa simplificada" que pode resumir o cânone hegemônico das representações de um determinado conflito contra o qual podemos projetar uma obra em particular. Para entender, portanto, a tese do presente trabalho de que " $\mathrm{Mu}$ lher Maravilha é um filme da Segunda Guerra Mundial que se passa na Primeira Guerra Mundial", convém resgatar o que Hynes diz sobre o mito de cada um desses conflitos.

O livro A War Imagined consiste em um esforço de Hynes de mapear o Mito da Primeira Guerra Mundial desde o prelúdio do conflito, até a consolidação de sua narrativa no período entreguerras. Ao longo do estudo, o autor traz à tona as inúmeras contestações e dissonâncias entre diferentes escritores, poetas e artistas durante a guerra, e evidencia que a construção do mito foi um longo processo de disputa por hegemonia. Porém, removidas as dissonâncias, o autor propõe que o "mito da Primeira Guerra" pode ser reduzido da seguinte forma:

(...) uma geração de jovens inocentes, com suas cabeças cheias de altas abstrações como Honra, Glória e Inglaterra, foram à guerra para tornar o mundo um lugar seguro para a democracia. Eles foram massacrados em batalhas estúpidas planejadas por generais estúpidos. Aqueles que sobreviveram ficaram chocados, desiludidos e amargurados por suas experiências de guerra, e viram que seu verdadeiro inimigo não eram os alemães, mas os velhos de seu próprio país que

\footnotetext{
4 I use that phrase in this book to mean not a falsification of reality, but an imaginative version of it, the story of the war that has evolved, and has come to be accepted as true. The construction of that story began during the war, and grew in the years that followed, assimilating along the way what was compatible with its judgments, and rejecting what was not. The Myth is not the War entire: it is a tale that confirms a set of attitudes, an idea of what the war was and what it meant.

5 “(...) I mean rather the simplified narrative that evolves from a war, through which it is given meaning: a Good War, a Bad War, a Necessary War. Myths seem to be socially necessary, as judgments or justifications of the terrible costs of war, but they take their shape at the expense of the particularity and ordinariness of experience (...). The myth of a war tells what is imaginable and manageable (...)."
} 
mentiram para eles. Eles rejeitaram os valores da sociedade que os mandou à guerra, e ao fazê-lo separaram sua própria geração do passado e de sua herança cultural. (...) [os elementos essenciais dessa estória] constituem um conjunto de disjunções abruptas (...) que podem ser reduzidas a duas proposições concisas: os velhos traem os jovens, o passado é remoto e inútil. (HYNES, 1992, loc. 74)6

Para definir o mito da Segunda Guerra Mundial, em The Soldiers' Tale, Hynes compara o conflito com a Primeira Guerra, de forma a traçar uma definição em oposição; se a Primeira Guerra foi o conflito da desilusão, da traição e da ruptura, a Segunda Guerra é mitologizada como a "Guerra Boa" ou, no mínimo, como a "Guerra Necessária" - principalmente em função da tangibilidade de seu inimigo (o fascismo internacional), ausente no conflito anterior. Havia na Segunda Guerra Mundial o que Hynes definia como uma "diferença em termos de autoridade moral":

A Primeira Guerra Mundial começou no idealismo, mas perdeu sua certeza moral conforme os combates se acirravam. A Segunda Guerra começou com um senso de necessidade moral mais claro e nunca o perdeu. A maioria das pessoas aceitavam que o Nazismo era omal e, em menor grau e posteriormente, que os homens que comandavam o Japão eram maus também. Uma guerra contra esses inimigos era um "Guerra Boa" - uma frase que nunca se tornou um oximoro, nem sequer no fim, embora àquela altura sessenta milhões de seres humanos tivessem morrido. (HYNES, 1998, p. 111)7

Hynes propõe então que o mito da Segunda Guerra Mundial pode ser reduzido ao epíteto da "Guerra Boa". Para o autor, a força desse mito é tão forte que frequentemente ele não aparece de forma explícita nas narrativas, mas "por trás do relato - uma convicção não expressa, tão certa que não precisa ser dita, de que essa era uma guerra em que valia a pena lutar" (HYNES, 1998, p. 112) ${ }^{8}$. Ele acrescenta:

Essa é uma visão romantizada e esteticizada da guerra, a colocando em termos

$6(\ldots)$ a generation of innocent young men, their heads full of high abstractions like Honour, Glory and England, went off to war to make the world safe for democracy. They were slaughtered in stupid battles planned by stupid generals. Those who survived were shocked, disillusioned and embittered by their war experiences, and saw that their real enemies were not the Germans, but the old men at home who had lied to them. They rejected the values of the society that had sent them to war, and in doing so separated their own generation from the past and from their cultural inheritance. (...) [the essential elements of this story] constitute a set of abrupt disjunctions (...) which can be reduced to two terse propositions: the old betray the young; the past is remote and useless.."

7 There was also a difference in moral authority. The First World War began in idealism but lost its moral certainty as the fighting ground on. The Second War began with a clearer sense of moral necessity and never lost it. Most people accepted that Nazism was evil and, to a lesser degree and later, that the men who ran Japan were evil too. A war against those enemies was a "Good War" - a phrase that never became an oxymoron, not even at the end, though by then sixty million human beings had died.

8 But though "war between good and evil" doesn't appear explicitly in the narratives, it is there, behind the telling - an unexpressed conviction, so certain that it doesn't need to be said, that this was a war worth fighting. 
literários e teatrais de forma a obscurecer questões complexas; mas parece ser a forma que muitas pessoas a imaginaram e ainda imaginam. E o drama de fato estava lá; havia heróis e vilões. O que é mais importante é que eles nunca mudaram: no fim de tudo, os exércitos voltaram pra casa ainda certos de que o mesmo bem era bom, e de que os mesmos males eram maus. (HYNES, 1998, p. 113, grifo do autor $)^{9}$

Uma vez colocados os mitos da Primeira e da Segunda Guerra Mundial em contraste, suas diferenças são claras: o conflito de 1914 a 1918 foi uma campanha desmoralizante, cujos ideais ruíram diante do julgamento histórico, marcada por desilusão, por desconfiança nas altas patentes e pelo surgimento de um sentimento de empatia pelas tropas inimigas. Já o conflito entre o Eixo e os países Aliados é mitologizado como a "Guerra Boa", uma guerra de superioridade moral e princípios certos contra um inimigo que mesmo hoje ainda é representado como um verdadeiro "vilão" da vida real: o nazi-fascismo. Localizadas essas diferenças, convém então retornar à adaptação de Mulher Maravilha para o cinema.

\section{UM FILME SOBRE A PRIMEIRA GUERRA MUNDIAL}

Mulher Maravilha apresenta esforços claros de localizar o enredo durante a Primeira Guerra Mundial. Os elementos cenográficos, a toponímia e os protagonistas políticos do enredo, naturalmente, confirmam a ambientação: o figurino corresponde aos uniformes de soldados ingleses e alemães de 1918, os aviões caça do filme, como o pilotado por Steve Trevor, são modelos da Primeira Guerra, locais como as trincheiras e a Terra de Ninguém aparecem proeminentemente no longa, etc. Mas não é só no nível visual e cenográfico que o filme localiza temporalmente seu enredo: os principais traços do "mito" da Primeira Guerra estão presentes no filme - por vezes de forma quase didática. A alienação entre os combatentes do front e os generais que os comandam, por exemplo, se torna explícita em um diálogo entre Steve Trevor e um oficial de alta patente na Inglaterra, em que o espião diz que se o lançamento do novo gás mostarda de Ludendorff não for impedido, todos os soldados - ingleses e alemães - morrerão, ao que o oficial inglês o responde: "isso é o que soldados fazem".

Outro aspecto do mito da Primeira Guerra Mundial que é notável no filme, mencionado inclusive na entrevista citada anteriormente com a equipe de produção do longa, é o aspecto automatizado da guerra e a escala de destruição de seus armamentos. A "versão mais letal de um gás mostarda" desenvolvida pela Doutora Veneno para o general Ludendorff serve como uma metáfora para a submissão da ciência ao esforço de guerra e o uso de tecnologia de ponta como estratégia de assassinato em massa eficiente. Como se a mera intro-

$9 \quad$ This is a romanticized and aestheticized version of the war, putting it into literary and theatrical terms in order to obscure complex issues; but it seems to be the way many people imagined it and still do. And the drama was there all right; there were heroes and villains. What is more important, they never changed; at the end of it all, the armies went home still certain that the same goods were good, the same evils were evil. 
dução do gás como um dispositivo central no roteiro não fosse o bastante, um diálogo entre Diana e Trevor explicita essa relação: a amazona pergunta ao espião "Que tipo de arma mata qualquer coisa [no campo de batalha]?", e ele lhe responde "Nessa guerra? Qualquer tipo." 10

A desilusão da guerra é também objeto de representação no filme. Uma cena em particular parece ilustrar esse aspecto do mito de forma notável, sem lançar mão de diálogos. Quando Diana e Trevor estão a caminho do front, eles se misturam a um grande grupo de novos soldados que também estão se preparando para embarcar. A cena é filmada em uma ponte, onde do lado direito - onde estão Diana e Trevor - caminham soldados jovens, sorridentes, cantando canções e conversando em voz alta, e do lado esquerdo vê-se soldados feridos retornando do front, alguns inclusive sendo carregados, com corpos mutilados, rostos tristes e uniformes rasgados.

Em certa medida, a própria noção de que os soldados adversários não eram os verdadeiros inimigos é também contemplada no filme. Ao final do longa, é revelado que de fato a guerra estava sendo causada pela influência do deus da Guerra Ares - porém, ao contrário do que Diana imagina inicialmente, ele não está disfarçado como o general alemão Ludendorff, mas sim como Sir Patrick Morgan, um membro do Gabinete Imperial de Guerra, superior de Steven Trevor e, supostamente, um dos maiores defensores do armistício. A revelação de que Morgan - um oficial inglês - é na verdade Ares, parece confirmar a narrativa de que a guerra foi uma grande mentira contada a jovens soldados para lutar contra outros jovens soldados que nunca lhe fizeram mal algum em nome de princípios vagos como "Honra", "Glória" e "Inglaterra", como proposto por Hynes em sua definição do mito da Primeira Guerra Mundial.

Somados todos esses aspectos, é evidente que Mulher Maravilha é um filme que busca representar a Primeira Guerra Mundial de forma coerente com seu mito da guerra - chegando a expor os aspectos desse mito de forma explícita e quase didática. Mas esses aspectos todos parecem estar em um nível puramente narrativo, contemplados no roteiro e na ambientação. Ao aprofundarmos a investigação de aspectos semióticos do filme, algumas fissuras começam a se tornar evidentes.

\section{UM FILME DE SEGUNDA GUERRA MUNDIAL}

Há uma cena em Mulher Maravilha que é de particular interesse: por volta do final do primeiro ato do filme, Diana conhece as trincheiras do front ocidental pela primeira vez. Uma camponesa alemã a implora pra que ajude civis que estão em um pequeno vilarejo sitiado além da trincheira inimiga. A heroína faz menção de ir ajudá-los, mas Steve Trevor a diz que isso é impossível: a vila está além da Terra de Ninguém - a No Man's Land -, o espaço intransponível entre as duas trincheiras. O espião a explica que nenhum homem ("no man") consegue atravessar a faixa, devido ao fogo inimigo intenso vindo do outro lado. Trevor ainda completa com um dado historicamente preciso: aqueles homens estavam alocados naquela trincheira há um ano, e mal tinham avançado polegadas. Diana não aceita

10 "What kind of weapon kills anything?" "In this war? Any kind". 
a argumentação, se despe do sobretudo que estava vestindo e revela seu icônico uniforme de amazona por baixo, com seu escudo, sua espada, seus braceletes e seu laço. Sob olhares incrédulos de soldados britânicos, ela sobe a escada para fora da trincheira e avança rumo à Terra de Ninguém. Quando as linhas inimigas abrem fogo contra a heroína, ela deflete os tiros com seus braceletes - em câmera lenta, num enquadramento dramático filmado de baixo para cima. A partir daí, Diana corre em direção à trincheira alemã, usando de seu escudo e seus braceletes para avançar, enquanto a música tema da personagem ressoa em um arranjo orquestral épico de fundo. Seu avanço inspira os demais soldados britânicos que também deixam as trincheiras e avançam pela Terra de Ninguém, até que eventualmente a heroína consegue alcançar a vila e libertá-la do exército inimigo.

Essa é uma cena central do filme - ela é o primeiro momento em que vemos Diana usando seu icônico uniforme de super-heroína e é uma cena amplamente usada nos trailers e pôsteres promocionais do longa. Mas, mais do que isso, creio que essa cena pode ser usada de forma metonímica para compreender a inadequação na representação que o filme faz da Primeira Guerra Mundial como um todo.

É importante relembrar que, diferentemente da Segunda Guerra Mundial, onde avanços e retrocessos das linhas eram registrados semanalmente na forma de mapas animados nos rolos de filme de notícias projetados nos cinemas, a Primeira Guerra teve uma geografia consideravelmente estável - ou, é possível ainda dizer, estática. O sistema de trincheiras que cruzava a Europa de norte a sul no Front Ocidental se deslocou muito pouco ao longo dos quatro anos de guerra. O avanço era praticamente uma impossibilidade.

Do inverno de 1914 até a primavera de 1918 o sistema de trincheiras era fixo, movendo aqui e ali algumas centenas de jardas, movendo em grandes ocasiões até algumas milhas. Papelarias de Londres que vendiam mapas se sentiam à vontade para estocar "mapas do 'Front Ocidental' com uma grossa e ondulante linha preta desenhada de Norte a Sul, ao longo da qual estava impresso 'Linhas Britânicas'. (FUSSEL, 2000, p. 36) ${ }^{11}$

A estagnação das posições é uma marca distintiva da Primeira Guerra Mundial, e um aspecto central de seu mito. Quando a Mulher Maravilha cruza sozinha a Terra de Ninguém, e com isso motiva uma unidade inteira do exército britânico a acompanhá-la e tomar a trincheira inimiga, o que está em questão é muito mais profundo do que uma mera imprecisão histórica: ao cruzar a Terra de Ninguém, Diana está cruzando os limites do mito da guerra, rompendo com um de seus maiores paradigmas. Um interessante exercício é comparar a cena com outras cenas de tentativas de travessia da Terra de Ninguém encenadas pelo cinema, como, por exemplo, no clássico filme de Stanley Kubrick Glória Feita de Sangue (1957). Se, em Mulher Maravilha a travessia é justamente a cena de virada do filme, onde a personagem de Diana se consolida como a super-heroína de guerra, no filme de Kubrick a fracassada tentativa de travessia é o mote para o julgamento exemplar em corte marcial

11 From the winter of 1914 until the spring of 1918 the trench system was fixed, moving here and there a few hundred yards, moving on great occasions as much as a few miles. London stationers purveying maps felt secure in stocking "sheets of 'The Western Front' with a thick wavy black line drawn from North to South alongside which was printed 'British Line”. 
de três soldados por "covardia" ao recuarem após receberem ordens de alcançar as linhas inimigas. O avanço de Diana rumo às trincheiras alemãs remete de forma muito mais forte ao cinema da Segunda Guerra Mundial, em filmes como O Portal da Glória (1949, Sands of Iwo Jima, no original), de Allan Dwan, ou o clássico épico do desembarque na Normandia O Mais Longo dos Dias (1962, The Longest Day, no original), de Ken Annakin, Andrew Marton et al - ambos filmes que retratam longas cenas de avanço e conquista de território inimigo.

Como mencionado, a cena da Terra de Ninguém em Mulher Maravilha pode ser entendida como uma metonímia para o filme como um todo. O procedimento que a cena opera é: localizar a cena em aspectos cenográficos e de enredo que a fixam na Primeira Guerra Mundial - no caso, a trincheira e a Terra de Ninguém -, mas trabalhar a cena de uma forma que deve muito mais às representações da Segunda Guerra Mundial - no caso, ao incluir o avanço e conquista de território inimigo.

Esse procedimento é operado em uma série de instâncias no filme. A representação dos vilões é uma delas. Como mencionado anteriormente, o filme parece tentar comunicar a tese de que, na Primeira Guerra, os soldados das fileiras adversárias não eram os inimigos, mas sim os oficiais de alta patente, principalmente na decisão de caracterizar o vilão Ares como um oficial da inteligência britânica. Contudo, o tratamento dispensado aos "inimigos da Inglaterra" no filme parece sugerir que esse esforço de aproximação é consideravelmente insincero. O filme não se aprofunda em nenhum personagem alemão, com a exceção de Ludendorff e da Doutora Veneno. Os soldados alemães são representados como uma massa amorfa de uniforme e fuzis em punho, prontos para impedir o avanço da unidade liderada por Diana - e devidamente nocauteados pela heroína, um após o outro. Não há nada remotamente parecido, em Mulher Maravilha, com a antológica cena em que Paul Bäumer mata um homem pela primeira vez em combate corpo-a-corpo em Nada de Novo no Front.

É ainda notável como os únicos personagens alemães que têm algum desenvolvimento - Ludendorff e Doutora Veneno - são, justamente, os principais vilões (considerando que Ares não se revela até os últimos trinta minutos de filme). A própria personagem da Doutora Veneno é digna de nota nesse aspecto: o topos do "cientista maluco alemão", que faz experimentos cruéis para desenvolver armas mortais não é nada comum na literatura da Primeira Guerra Mundial. No entanto, as narrativas da Segunda Guerra são repletas de tais personagens, frequentemente inspiradas no temido Josef Mengele, o infame "Anjo da Morte" de Auschwitz, médico alemão que praticava experimentos mortais em pacientes humanos no campo de concentração. É interessante notar que, embora o filme pareça querer sugerir que "oficiais de ambos os lados estavam errados" ao colocar Ares infiltrado na inteligência britânica, é no oficialato alemão - na figura de Ludendorff - que o filme coloca a responsabilidade por criar a arma mortal que exterminaria toda a humanidade.

A insinceridade da aproximação entre alemães e ingleses no filme se torna particularmente notável - e, arrisco dizer, cínica - no final do filme: quando Ares é derrotado, soldados de lados inimigos se abraçam, como se, por fim, libertos do feitiço do Deus da Guerra. Contudo, na cena seguinte, segundos depois, é nas ruas de Londres e agitando bandeiras inglesas que os protagonistas do filme celebram sua vitória, e o fim da guerra. É claro que os ingleses estariam celebrando - mas sabendo o teor do tratado de Versalhes que acabara 
de ser assinado, e o processo histórico que ele coloca em curso para a Alemanha nas décadas seguintes, parece ser no mínimo inocente e no máximo irresponsável representar o final da guerra e a vitória dos Aliados com tal grau de otimismo.

Outro aspecto recorrente das narrativas de Segunda Guerra Mundial, ausente das narrativas de Primeira Guerra, e que Mulher Maravilha parece buscar reproduzir, é o topos do "pelotão étnico" - um recurso muito comum em filmes de combate estadunidenses. A ideia de um pelotão com representantes de diferentes etnias - ou, talvez seria mais preciso dizer, de diferentes estereótipos nacionais - que pudesse representar o famoso melting pot da diversidade étnica estadunidense pode ser vista em filmes como Sahara (1943), de Zoltán Korda, em que o pelotão que acompanha o Sargento Joe Gunn - representado pelo galã Humphrey Bogart - inclui um italiano, um francês, um negro (de origem sudanesa), um irlandês, e alguns outros. ${ }^{12}$ Esse mesmo recurso do "pelotão étnico" parece se repetir em Mulher Maravilha, na composição da intrépida unidade de espionagem montada por Steven Trevor que inclui, além do espião inglês e de uma guerreira amazona, um contrabandista nativo-americano, um franco-atirador escocês e um vigarista francês.

Para além dos exemplos acima elencados, o filme está ainda repleto de rimas visuais possíveis com clássicos do cinema de Segunda Guerra Mundial; o desembarque de soldados alemães na praia de Themscyra remete diretamente à cena do desembarque dos soldados aliados na Normandia em O Resgate do Soldado Ryan (1998), de Steven Spielberg, e a sequência de combate urbano que sucede a cena da trincheira discutia acima alude a batalhas travadas nas ruas das cidades europeias capturadas em filmes como Círculo de Fogo (2001, Enemy at the Gates, no original), de Jean Jacques Annaud, ou Anonyma - Uma Mulher em Berlim (2008, Eine Frau in Berlin, no original), de Max Färberböck.

Mas talvez mais do que todos os aspectos discutidos, há um tom que subjaz toda a narrativa do filme que parece ser incompatível com a forma que representamos a Primeira Guerra Mundial, com o mito desse conflito. Mulher Maravilha é um filme otimista, heroico, com um vilão claro - Ares -, que, uma vez derrotado, resolve o conflito não só da trama, mas daquele mundo ficcional por inteiro. É curioso notar que, como mencionado anteriormente, a diretora Patty Jenkins cita o fato da Primeira Guerra ser um conflito onde "não era claro quem estava certo" como uma das motivações para escolher a ambientação do filme - mas, ao contrário do conflito real, em Mulher Maravilha há sim linhas muito claras separando o "bem" do "mal". Talvez nada mais traduza esse otimismo inabalado do filme do que uma frase no monólogo final da protagonista: "E agora eu sei que apenas o amor pode verdadeiramente salvar o mundo". ${ }^{13}$

12 Uma discussão mais aprofundada sobre a representação de pelotões étnicos em filmes hollywoodianos sobre a Segunda Guerra Mundial é feita por Thomas Burns em um trabalho ainda não publicado, Blockbusters \& Duds: The Hollywood Combat Film.

13 And now I know that only love can truly save the world. 


\section{AS VÍTIMAS DE UMA MENTIRA TERRÍVEL E MUITO VELHA}

A Mulher Maravilha é um produto da Segunda Guerra Mundial, produto de uma certeza moral inabalada de que há um grande mal a ser combatido, de que existe uma luta justa, e de que a humanidade pode triunfar. Os super-heróis da Era de Ouro dos quadrinhos representavam toda a esperança e otimismo inabalável de um momento histórico em que a luta contra o fascismo parecia ser uma causa capaz de unir os mais diversos povos.

Ao deslocar uma personagem desse contexto para o pessimismo e desilusão da Primeira Guerra Mundial, corre-se grandes riscos. O maior deles, creio, é o de fazer qualquer crítica à própria guerra, às suas motivações ou ao seu desenlace, soarem insinceras. Mais do que isso: ao usar das estratégias narrativas de representação da Segunda Guerra Mundial para representar a Primeira Guerra, um filme como Mulher Maravilha acaba incorrendo em uma apologia e justificação do conflito de 1914. Slavoj Žižek oferece uma discussão sobre a "humanização" de soldados do Mossad feita por Steven Spielberg em seu filme Munique (2005) que, creio, oferece um paralelo interessante:

[E]le [o filme de Spielberg] quer ser "objetivo", apresentando a ambiguidade e a complexidade moral, as dúvidas psicológicas e a natureza problemática da vingança do ponto de vista israelense. No entanto, essa abordagem "realista" apenas redime ainda mais os agentes do Mossad: "Veja, eles não são só assassinos frios, são também seres humanos com suas dúvidas - eles duvidam, mas os terroristas palestinos não...”. (ŽIŽEK, 2018, p.8)

É notável que Žižek ainda acrescenta, a seguir, que “[é] interessante notar a presença cada vez mais constante de "humanizações" similares na recente onda de histórias de super-heróis que fizeram sucesso nos cinemas (Homem-Aranha, Batman, Hancock...)” (p.10). Se estivesse escrevendo hoje, o filósofo esloveno talvez incluísse Mulher Maravilha na lista.

A maior gravidade do projeto que Patty Jenkins e o produtor Zack Snyder empreendem não reside num simples "anacronismo" ou numa "falta de rigor histórico". Existe um verdadeiro mal em usar do mito da Segunda Guerra Mundial para modelar nosso olhar sobre a Primeira.

Hynes define o mito da Segunda Guerra Mundial como a "Guerra Boa". Mas esse mito, assim como todo mito da guerra, conta uma história incompleta, conta do que é "imaginável" e "administrável", como coloca o teórico. O mito da Segunda Guerra Mundial deixa de fora crimes de guerra cometidos pelos países aliados; ele ignora o bombardeio de Dresden pelas forças aéreas britânica e estadunidense, ignora o estupro sistemático de camponesas na Prússia Oriental pelo exército vermelho e, de forma particularmente torpe, busca justificar o ataque nuclear nas cidades de Hiroshima e Nagasaki pelos Estados Unidos. O Mito da Segunda Guerra Mundial acaba por esconder o fato de que, independentemente do quão moralmente justificável uma guerra possa ser, ela será sempre um evento histórico catastrófico, cruel e vil.

O Mito da Primeira Guerra Mundial se apresenta como praticamente o oposto do de sua sucessora: aqui, a guerra é representada como uma desilusão, uma mentira contada 
para levar jovens a se matarem sem motivo, um jogo cruel desenhado por velhos poderosos para proveito próprio, ao custo de milhões de vidas. A construção desse mito, como Hynes desenvolve longamente em $A$ War Imagined, não aconteceu da noite para o dia. Inúmeros livros que se opunham à guerra foram censurados dos dois lados do front; "poetas oficiais" eram eleitos por governantes para celebrar as glórias da guerra; livros que enalteciam o combate e aqueles que denunciavam seus horrores disputaram espaços nas prateleiras por anos. A construção do mito da Primeira Guerra Mundial - assim como a construção de qualquer mito da guerra - foi uma disputa por hegemonia. Essa disputa, creio que podemos dizer hoje, mais de cem anos após do fim do conflito, foi ganha pelo discurso democrático e progressista. Após décadas da construção desse mito, a Primeira Guerra Mundial é amplamente entendida hoje como um exemplo paradigmático de porque uma guerra - especialmente uma "guerra total" - nunca é algo a ser almejado.

Ao projetar uma estória da Primeira Guerra Mundial sobre uma estrutura narrativa da Segunda Guerra Mundial, o que Mulher Maravilha parece fazer é retroceder em cem anos a disputa hegemônica empreendida por décadas de uma intelectualidade antibelicista. Ao invés de, por exemplo, oferecer uma narrativa que avance para desconstruir o mito da "Guerra Boa" da Segunda Guerra Mundial, o filme oferece um esforço de justificativa dos horrores de 1914 a 1918. Essa problemática é talvez melhor sintetizada pelo autor e veterano da guerra do Vietnã Tim O’Brien, em sua coletânea de contos The Things They Carried:

Uma verdadeira estória de guerra nunca é moral. Ela não instrui, nem encoraja virtude, nem sugere modelos apropriados de comportamento humano, nem refreia homens de fazer as coisas que homens sempre fizeram. Se uma estória de guerra parece moral, não acredite nela. Se no final de uma estória de guerra você se sentir edificado, ou se você sentir que algum pedacinho de retitude foi resgatado do resto dos dejetos, então você foi feito de vítima por uma mentira terrível e muito velha. (O’BRIEN, 2009, p. 65) ${ }^{14}$

O monólogo final de Mulher Maravilha parece tentar oferecer uma verdadeira "moral da história", ao concluir que "apenas o amor pode salvar o mundo". Com isso, ele parece ser mais uma em uma longa lista de narrativas de guerra que serviram para contar essa "mentira terrível e muito velha."

\footnotetext{
14 A true war story is never moral. It does not instruct, nor encourage virtue, nor suggest models of proper human behavior, nor restrain men from doing the things men have always done. If a story seems moral, do not believe it. If at the end of a war story you feel uplifted, or if you feel that some small bit of rectitude has been salvaged from the larger waste, then you have been made the victim of a very old and terrible lie.
} 


\section{REFERÊNCIAS BIBLIOGRÁFICAS}

ALL-STAR COMICS. Nova Iorque: All-American Publications, n. 8, vol. 1. 1941.

FUSSEL, Paul. The Great War and Modern Memory. Nova Iorque: Oxford UP, 2000.

HARRIS, Mark. Five Came Back: A Story of Hollywood and the Second World War. Nova Iorque: Penguin, 2014. E-book Kindle.

HYNES, Samuel. A War Imagined: The First World War and English Culture. Londres: Pimlico, 1992. E-book Kindle.

The Soldiers' Tale: Bearing Witness to Modern War. Nova Iorque: Penguin, 1998.

LEPORE, Jill. The Surprising Origin Story of Wonder Woman. Smithsonian.com Out. 2014. Disponível em: < https://www.smithsonianmag.com/arts-culture/origin-story-wonder-woman-180952710/ >.

O’BRIEN, Tim. The Things They Carried. Nova Iorque: First Mariner, 2009.

QUATTRO, Ken. The New Ages: Rethinking Comic Book History. Comicartville Library. 2004. Disponível em: < https://web.archive.org/web/20150905115607/http://www.comicartville.com/ newages.htm $>$.

SPERLING, Nicole. Wonder Woman filmmakers explain why they changes heroine's origin story. Entertainment Weekly. 30 mai. 2017. Disponível em: < https://ew.com/movies/2017/05/30/wonderwoman-world-war-i-setting/ >.

SPIEGELMAN, Art. Um super-herói contra o Caveira Laranja. Folha de S. Paulo, 20 ago. 2019. Quatro Cinco Um: a revista dos livros. Disponível em: < https:/quatrocincoum.folha.uol.com.br/br/artigos/q/ um-super-heroi-contra-o-caveira-laranja $>$.

WONDER WOMAN. Direção de Patty Jenkins. Burbank: Warner Bros. Pictures, 2017. Streaming (141 min.).

ŽIŽEK, Slavoj. Hollywood hoje: Notícias de um Front Ideológico. Trad. Luís Leitão \& Ricardo Gozzi. In: Lacrimae Rerum: Ensaios sobre cinema moderno. São Paulo: Boitempo, 2018. 